\title{
Implementing STEAM in the Early Childhood Classroom
}

\author{
Nancy K. DeJarnette ${ }^{1 *}$ \\ 1 University of Bridgeport, 126 Park Avenue, Bridgeport, CT 06604, USA \\ *Corresponding Author: ndejarne@bridgeport.edu \\ Citation: DeJarnette, N. K. (2018). Implementing STEAM in the Early Childhood Classroom. European \\ Journal of STEM Education, 3(3), 18. https://doi.org/10.20897/ ejsteme/3878
}

Published: September 6, 2018

\begin{abstract}
STEAM (Science, Technology, Engineering, Art, and Math) education has received growing attention over the past decade, primarily within the middle and high school levels. This article focuses on the need for STEAM education at the early childhood level. Preschool children have a natural disposition toward science with their sense of curiosity and creativity. This ethnographic research involved professional development for 50 in-service preschool teachers in an urban high-needs area of the northeastern United States. The researcher explored how providing hands-on professional development, consistent support, and rich resources for STEAM lesson implementation into the early childhood curriculum would impact the dispositions, self-efficacy, and rate of implementation for teachers. The study also involved observation of the reception of STEAM instruction by preschool children. Data was collected through pre and post surveys, teacher interviews, and field observations. Findings revealed an increase in positive dispositions and self-efficacy of preschool teachers, however, the rate of implementation of STEAM lessons by the teachers was initially limited. The reception of the STEAM lessons by these high-needs preschool children was phenomenal with high levels of engagement and cooperation. More research needs to be done in the area of STEAM implementation in the PK-12 classrooms to incorporate engineering education.
\end{abstract}

Keywords: STEM education, early childhood STEAM, early science education, preschool STEM, preschool STEAM

\section{INTRODUCTION}

There is a growing need in the United States to produce more skilled laborers in the areas of science, technology, engineering, and math (STEM) (Gomez and Albrecht, 2013; Nugent et al., 2010). According to the National Center for Education Statistics (2009), the United States has fallen behind other developed countries in math and science (Myers-Spencer and Huss, 2013). If the U.S. wants to support growing technological innovation, then it is important to increase the amount of positive exposures and experiences to STEM fields for PK-12 students (Aronin and Floyd, 2013). With greater attention to the need for STEM education in recent years, United States youth have shown some improvement in the areas of math and science performance, but still lag behind their international peers (Desilver, 2015).

\section{STEAM Adds the Arts}

There is a growing trend in adding the arts to STEM and making it STEAM (Jones, 2011). STEAM is important because it helps teachers incorporate multiple disciplines at the same time and promotes learning experiences that allow children to explore, question, research, discover, and exercise innovative building skills (Colker and Simon, 2014). Including the arts in the STEM disciplines is a natural fit because of STEAM's emphasis on creativity and design (Sharapan, 2012). STEAM concepts are second nature for children, as they like to explore and experiment 
within their natural environment. Adding art provides additional options for educators to present STEM concepts to children, especially at the elementary and early childhood levels. Robelen (2011) states that STEAM integration allows for intersection of the arts with the STEM fields which not only can enhance student engagement and learning, but also help unlock creative thinking and innovation. The nature of the arts and STEM both lend themselves to hands-on learning and production.

\section{Early Exposure}

Research has shown that providing meaningful hands-on STEAM experiences for early childhood and elementary age children positively impacts their perceptions and dispositions towards STEAM (Bagiati et al., 2010; Bybee and Fuchs, 2006; DeJarnette, 2012). STEAM concepts are not too difficult for preschoolers (Kropp, 2014) who are persistent and determined when building designs; they naturally try to fix them when things don't quite work out the way they wanted. Van Meeteren (2015) states,

Engineers often define their work as design under constraint. In the block center, preschoolers work hard to build structures under many constraints or limitations. They must consider space, shapes, sizes, materials, the numbers of blocks available, and of-course gravity. Preschoolers are budding engineers! (p. 30)

Young children need time to explore, create, and innovate. They want to learn basic knowledge and gain understanding of how the world works (Koester, 2013). Preschool children have a natural disposition toward science with their sense of creativity, curiosity, and persistence (Banko et al., 2013). STEAM activities provide preschoolers with a natural environment for collaboration and communication. They are capable of discussing different strategies and suggestions for a simplistic engineering design.

The preschool age is a great age in which to introduce science literacy (Koester, 2013). Early learning librarians can utilize children's literature to design STEAM activities in the library and begin building a foundation for STEM concepts (Kropp, 2014; Myers-Spencer and Huss, 2013). Preschoolers have a natural sense to work with materials, try things out, and problem-solve. Engineers identify a problem, design and construct a solution, test their product, and work to improve it (Jackson et al., 2011). Testing products is a key aspect of the engineering design loop. In STEAM education, teachers need to question their young students and encourage critical thinking about their designs and ways in which to improve them (Ingram, 2014). This instructional strategy will easily turn play into learning.

There are many benefits for young children from early exposure to STEAM. Integrated and exciting learning experiences improve students' interests and learning in STEM and helps prepare them for the $21^{\text {st }}$ Century. In Becker and Kyungsuk's (2011) research, cohesive STEAM lessons within the curriculum identified a positive impact on student achievement with students at the elementary level. When children are introduced to STEAM at an earlier age, there tends to be less gender-based stereotypes and fewer obstacles regarding STEM (Kazakoff et al., 2013; Davidson, 2011). However, little research exists regarding the impact of STEAM initiatives at the early childhood level (Moomaw, 2012).

\section{Professional Development for Teachers}

Science classrooms need to exhibit more critical thinking, inquiry and problem-solving activities that promote process skills rather than simply content knowledge (DeJarnette, 2012). Middle and high school teachers are specifically trained within their STEM disciplines, however, at the elementary and early childhood level, teachers have had little or no instruction. When faced with this new emphasis on STEAM education in the primary grades, teachers are often intimidated, lack self-efficacy, and reveal negative dispositions as a result of their lack of training (Jamil, Linder and Stegelin, 2018). When they feel inadequate with certain content areas, they tend to spend less time teaching that particular content with their students. Nugent et al. (2010) research revealed that teachers significantly increased their knowledge of engineering and developed more positive attitudes towards STEM, increasing their self-efficacy and confidence in teaching STEM lessons, after receiving effective professional development. Self-efficacy is defined as one's impression of their own proficiency on a task (Myers, 2014). It resembles one's contemplation and discernment of their own abilities on a given performance. This lack of STEM or STEAM training for elementary and early childhood teachers brings new urgency for quality professional development in light of the newly released Next Generation Science Standards (NGSS), which emphasize K-12 engineering and technology education.

\section{Next Generation Science Standards (NGSS)}

In the spring of 2013, the Next Generation Science Standards (NGSS) were officially released in the United States. States across the nation have slowly been adopting the new standards. Currently in mid-2018, 19 states and the District of Columbia have adopted the standards and have implementation schedules. These standards were 
developed by 26 lead state partners (Next Generation Science, 2016). The NGSS emphasize scientific inquiry, engineering design, and require K-12 students to have the ability to link broad concepts across scientific fields. The inclusion of K-12 engineering education will bring challenges and anxiety to many teachers who have not been adequately trained on this specific content and skill set, especially at elementary and early childhood levels. With the adoption of the NGSS by the states, there is a realization that adequate professional development will be required for teachers before they can fully implement the new standards, resulting in slow adoption rates as well as implementation schedules (Next Generation Science, 2016). The inclusion of K-12 engineering education reveals that science educators at the highest levels are in agreement that STEM concepts are not only appropriate for early childhood, but that young children are also capable of completing simple engineering design challenges and experience success with STEM skills (Moomaw and Davis, 2010).

\section{Theoretical Perspective}

The theoretical framework for this study was based on the sociocultural theory leading to the Constructivist theory, which is an approach to learning based upon the work of Vygotsky (1978). Sociocultural theory accentuates the importance of students' interaction with others and their environment in order to gain understanding. Constructivist theory emphasizes the importance of providing students with authentic learning experiences where they can relate real world problems and situations to the task at hand (Wilson, 1996). The unique structure of the professional development workshop (provided for the teachers in this study) reflected these learning theories through the hands-on modeling of STEAM lessons. Research has shown that when professional development for teachers focuses on specific teaching practices, it results in an increase of the use of those practices in the classroom (Desimore et al., 2002; Huffman et al., 2003).

\section{Research Questions}

The research questions for this study were as follows:

1. What will the result of providing professional development in STEAM (Science, Technology, Engineering, Arts and Math) initiatives in high-needs schools have on the dispositions of early childhood teachers toward STEM as they implement?

2. What will the result of providing professional development in STEAM in high needs schools have on the self-efficacy of early childhood teachers as they implement?

3. What will the result of providing professional development in STEAM initiatives in high needs schools have on the rate of implementation of STEAM pedagogy in the early childhood classroom?

The hypotheses for the study posits that preschool teachers in high-needs schools will show a positive increase in their dispositions, self-efficacy, and rate of implementation regarding STEAM lessons in their classrooms after receiving professional development, in-class support, and needed resources.

\section{METHODOLOGY}

This research is based on a phenomenological approach focusing on the "lived experiences" of the participants within the professional development provided and its aftermath.

\section{Participants \& Setting}

The study involved 50 in-service preschool teachers in an urban high-needs area in the northeastern United States. These teachers taught children ages three to five. Ninety percent of the teachers were female with a wide range of diversity represented, the majority being African American. Fifty percent of the teachers had ten or more years of teaching experience, forty percent had 4-9 years' experience, with the remaining ten percent having less than four years' experience.

These preschools were located in an urban center with approximately 150,000 people. The median household income in 2014 was around $\$ 43,000$ per year, which is well below the state average (City-data, 2016). Ethnicities of the city population included 39\% Hispanic, 34\% African American, and 22\% Caucasian. The crime index for this city is 449.7, which is nearly double the US average. The difficult issues surrounding this city (crime, poverty, unemployment, etc.) are similar to challenges in other urban centers around the United States.

\section{The Study}

In this phenomenological research study, the researcher provided two consecutive professional development workshops for 50 preschool teachers. The two workshops were offered three months apart with the first offered in February and the second in May, 2016. Each workshop was 90 minutes long with two back-to-back identical sessions serving 25 participants in each. The workshop content provided a brief overview of the newly adopted Next Generation Science Standards (NGSS) and the need for STEAM at the preschool level, followed by modeling a variety of hands-on age appropriate STEAM lessons appropriate for the preschool classroom. All lessons were 
directly related to children's literature and utilized recyclables and inexpensive everyday materials. Two different instructional formats were modeled for the teachers during these workshops. The first consisted of multiple STEAM learning centers. These learning centers included quick hands-on activities that exhibited simple engineering and science concepts appropriate for the preschool child to manipulate independently or with assistance. The second instructional format consisted of whole-class led STEAM lessons related to children's literature.

One example of a whole-class lesson utilized the children's book, The Gingerbread Man. After an oral reading of the story, the children are asked to design a different way for the gingerbread man to get across the river other than on the sly fox's head. The materials provided were various sizes of aluminum foil, foam board pieces, craft sticks, tape, and plastic straws. The engineering challenge was to design a boat for the gingerbread man that will hold the most weight (pennies or dominos) without sinking. Two small tubs of water were placed in different sections of the classroom to be used for testing. The participants were encouraged to follow the engineering design loop where they ask, imagine, plan, create, and improve their designs (Jackson et al., 2011). Upon implementation, the teachers are encouraged to discuss simple science concepts with the children as they engage in these STEAM activities.

Between the two workshop days, the researcher made herself available to provide in-class support for the implementation of STEAM lessons, however, no formal invitations were received. The researcher was however, invited to one of the preschool sites to provide STEAM demonstration lessons for the teachers within their classrooms. The school consisted of four preschool classrooms of children ages 4-5 with approximately 20 in each. While the researcher worked with the children directly on the STEAM lessons, the classroom teachers either assisted or observed. The four lessons were conducted over a two-day period with two lessons conducted each day.

Individual teacher interviews were conducted during the final professional development day. Random teachers were interviewed during the lunch that was provided. All interviews were recorded to ensure transcription accuracy with member checks. This workshop series was grant-funded and provided two STEAM lesson activity books for each teacher as a valuable resource for future implementation.

\section{Instruments \& Analysis}

Identical pre- and post- surveys were given to the teachers, which asked them to rate their level of comfort regarding STEM instruction utilizing a 5-point Likert scale. The Likert scale ratings consisted of $4=$ Extremely, 3 = Very, $2=$ Moderately, $1=$ Little, and $0=$ Not at all, in reference to their personal activity and confidence levels. The survey data was analyzed using Chi-square and Wilcoxon Tests. The Chi-square test is applied when you have two categorical variables from a single population to determine if there is a significant association. Wilcoxon tests are used to compare ordinal or nominal pre- and post- data collected from the same group (teachers). An Institutional Review Board (IRB) application was submitted and accepted by the university for this research. Teachers were informed about the study and voluntarily signed a letter of consent prior to participation. The survey was validated prior to the study using two pilot groups, the first with 25 pre-service teachers, and the second with ten in-service teachers. The survey questions are displayed in Table 1.

Table 1. Pre and Post-Survey of Teachers' Comfort with STEM Instruction

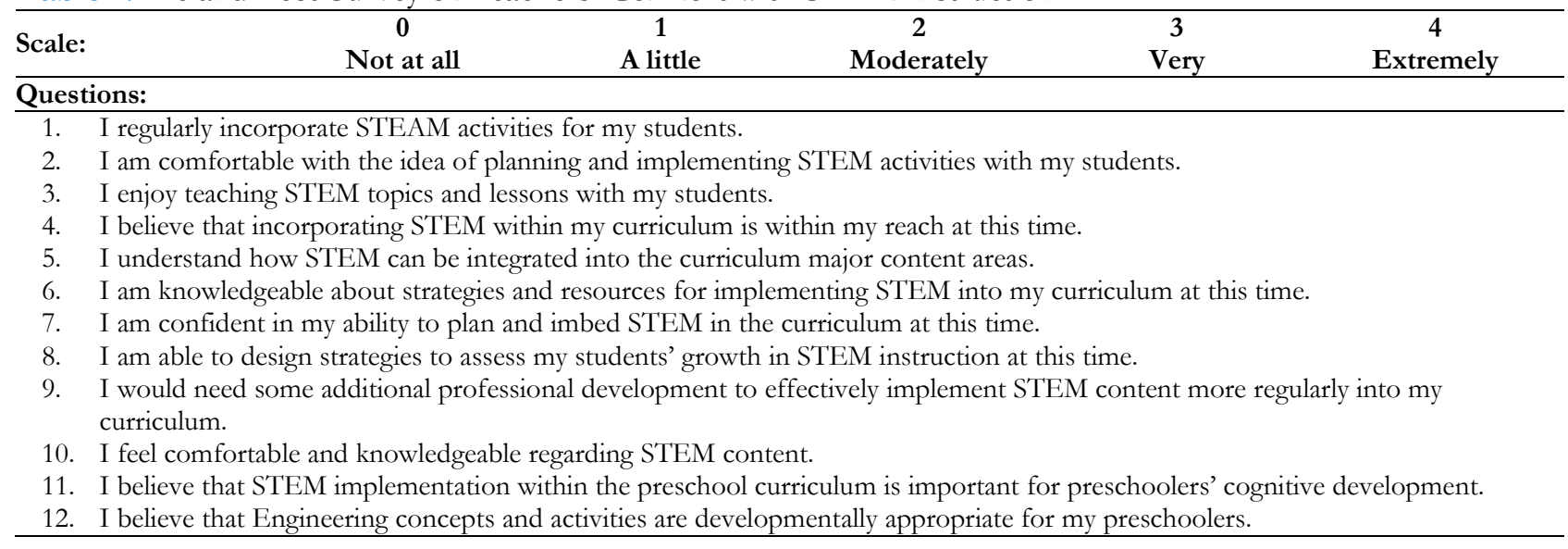

During the second professional development day, teacher interviews were conducted at random. The interview questionnaire was also validated prior to the study using the same two pilot groups as the survey. The teachers were asked a variety of questions about their current practices with STEAM instruction as well as their comfort levels with planning and delivering STEAM lessons. The teacher interview questionnaire is displayed in Table 2. 
Table 2. Interview Questionnaire of Teachers' Experiences with STEAM Instruction

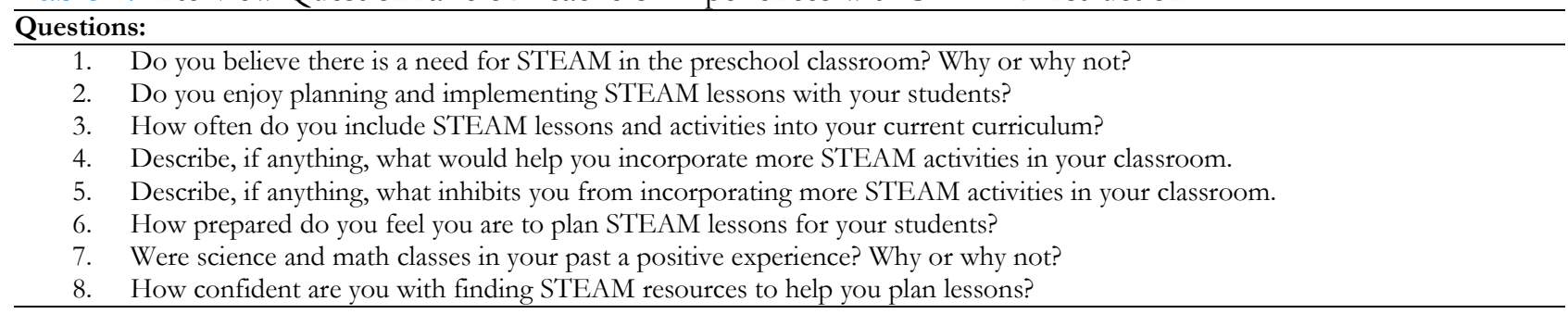

Field observations were recorded as a third data point in which the researcher served as a participant observer. Participant observation is a method in phenomenological research where the researcher is directly involved in the activities of the observation environment (DeWalt and DeWalt, 2011). These field observations included two professional development hands-on workshops for teachers as well as demonstration lessons provided by the researcher in four preschool classrooms. As a result, the researcher was entrenched within the culture of the research setting and interacted with both teachers during the workshop and the preschool students during the model lessons.

\section{FINDINGS}

\section{Surveys}

Fifty preschool teachers participated in the study and attended two days of professional development on implementing STEAM lessons into their preschool curriculum. They completed a pre survey prior to engagement in the STEAM workshops and a post survey at the end of the second day of the workshop. Out of the fifty teachers, thirty agreed to participate in the study and completed both surveys. The statistical results of the Chisquare analysis at alpha $<0.05$ for the pre and post surveys showed a statistically significant positive change in their confidence level regarding their ability to plan and implement STEAM lessons for their preschoolers as a result of the professional development. For the comparison of participants' answers before and after the professional development, a Wilcoxon test at the $<0.05$ significance level was also performed. The Wilcoxon Test results are displayed in Table 3 where the $p$ values indicate a statistically significant difference between pre and post data for those questions at the $<0.05$ significance level.

Table 3. Significance Found in Survey Questions

\begin{tabular}{ll} 
Question 2 & $\mathrm{p}<0.032$ \\
Question 6 & $\mathrm{p}<0.005$ \\
Question 8 & $\mathrm{p}<0.008$ \\
Question 9 & $\mathrm{p}<0.04$ \\
Question 10 & $\mathrm{p}=0.00$ \\
Question 12 & $\mathrm{p}<0.02$ \\
\hline Alpha $<0.05$ &
\end{tabular}

On question two, I am comfortable with the idea of planning and implementing STEM activities with my students, teachers showed the largest increase from pre to post survey with a statistical significance of $p<0.032$. This question in particular addressed research question number two, regarding their confidence and self-efficacy to plan and implement STEAM activities with their students. Teachers' self-efficacy towards STEAM increased as a result of the professional development. Descriptive results of questions four and seven were also in agreement with this finding as teachers showed an increase in their own abilities to incorporate STEAM activities in their classrooms. Question six which states, I am knowledgeable about strategies and resources for implementing STEM into my curriculum at this time, had significant results with $p<0.005$ demonstrating an increase in teachers' knowledge about strategies and resources for implementing STEM into their curriculum as a result of the professional development.

Descriptive results from question three, I enjoy teaching STEM topics and lessons with my students, showed a positive increase by 1.01 ratings according to the scale in teachers' dispositions towards STEAM. As a result of the workshop, teachers felt more comfortable with STEAM concepts and their own personal skills. Results of question ten, I feel comfortable and knowledgeable regarding STEM content, confirmed this also showing an increase in their own perceived knowledge of STEAM content with a statistical significance of $p<0.001$.

There was a minimal increase in question 12, I believe that Engineering concepts and activities are developmentally appropriate for my preschoolers, as teachers rated this question fairly high to begin with. The question rated high on the 
pre and post survey with a significance level of $p<0.02$, which indicates that the teachers believe that these concepts are not beyond the early childhood development stage.

Question nine, I would need some additional professional development to effectively implement STEM content more regularly into my curriculum, showed very little change with only a slight dip of .05 on the rating scale and significance rating of $p<0.04$. This indicates that teachers' perception from pre to post survey remained the same of their acknowledgement of needing additional professional development in order to effectively implement STEAM content regularly into their preschool curriculum. This indicates that while their self-efficacy and dispositions towards STEAM increased as a result of the professional development, they still did not feel confident enough to regularly implement. This confirms question one, I regularly incorporate STE AM activities for my students, which scored the lowest of all the questions on both the pre and post survey regarding their regular current implementation of STEAM activities. Even though the data showed an increase for implementation on the survey, when asked later during the interviews, none of the teachers had actually implemented a STEAM lesson within their classroom after the first training. The descriptive bar graph results of the survey can be seen in Figure 1.

\section{STEAM Pre \& Post Survey Results}

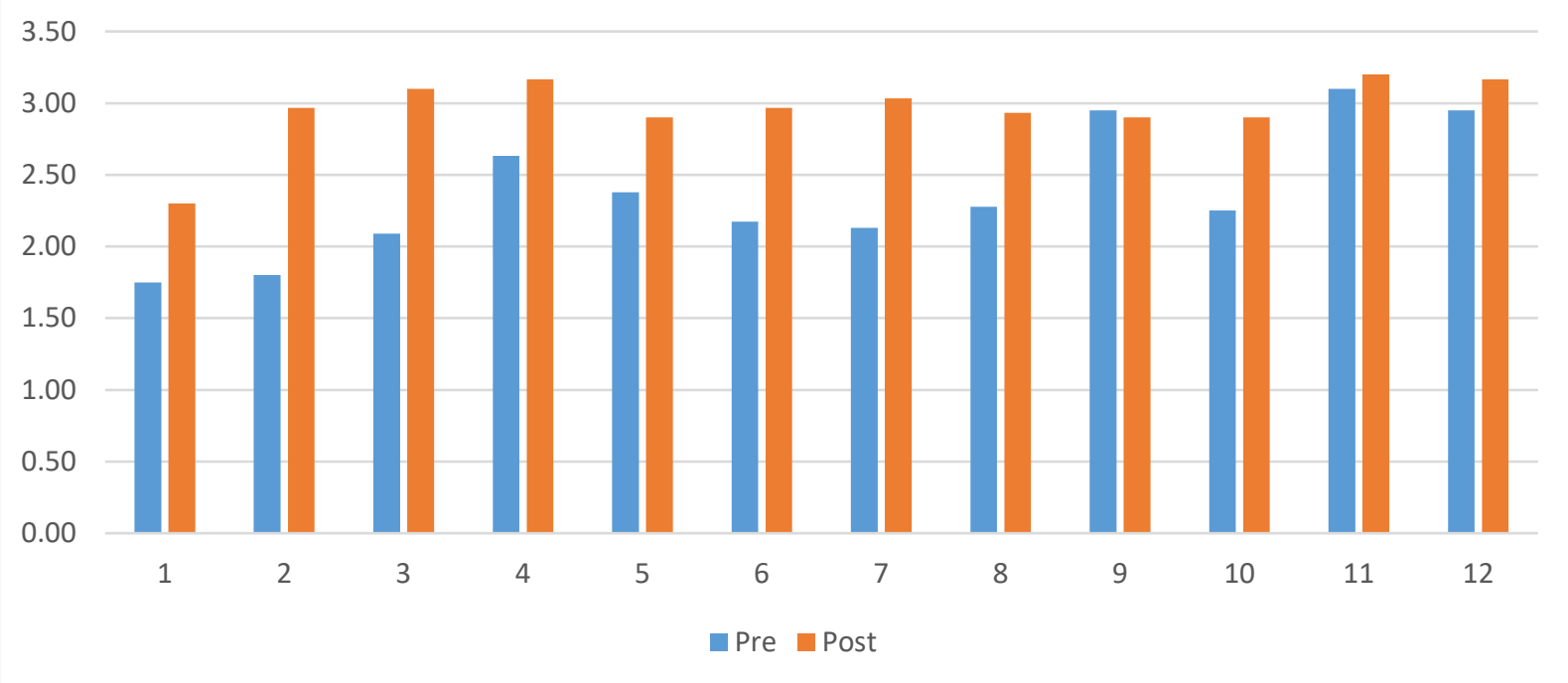

Figure 1. Preschool Teachers Pre and Post Survey Results

\section{Interviews}

After the second professional development offering, the researcher interviewed four individual teachers to seek their personal feelings towards STEAM instruction. Regarding question one, all four teachers were in agreement that there is a need for STEAM at the preschool level. One teacher stated, "STEM is a big topic right now, and it seems to have trickled down to our level, so it is needed."

Question three asked them how often they include STEAM lessons into their curriculum, and all four teachers stated that they had not yet attempted a specific STEAM lesson with their young students. Question five then asked what inhibited them from implementing more STEAM activities. One teacher stated, "It is still all too new to me, I am not sure how it would go teaching it [STEAM] to my kids." A second teacher stated, "You gave us a lot of resources, bowever, I feel like I need more time to really look through them and get comfortable with the STEAM content before I try it in my classroom." A third teacher said, "You modeled the STEAM activities with us, which was great, but I think I would need to see STEAM lessons modeled with children to help me feel more comfortable."

Question six asked how prepared the teachers felt to plan STEAM lessons for their students. All four teachers were in agreement that the professional development definitely helped them see what STEAM lessons looked like for the preschool classroom and that the resources provided were fantastic. They stated that they now felt more prepared as a result. However, they also reported that they still had reservations about their own abilities to implement it in their own classrooms. One teacher stated, "I feel much better now than I did before, and you modeled some great STEAM activities that I think I could do in my classroom with my kids, but I still think. I need a little more time." The last interview question asked about their confidence level in finding STEAM resources to help them plan lessons. All four teachers again stated that as a result of the workshop they felt more confident, since many great resources were provided by the researcher (books and websites) that will help them plan. 


\section{Field Observations}

During the two professional development workshop days, the teachers were pleasant and eager to participate in the hands-on STEAM modeled lessons. The teachers were fully engaged during the workshops. They were talking and laughing as they made their designs and moving through the engineering design loop. When asked if their preschool students would be successful with these STEAM activities, they all whole-heartedly agreed. Several groups went back to the testing table three and four times trying to improve their boat designs to hold even more weight. This simple act demonstrates the engagement of the teachers and their commitment to the STEAM process. The teachers consistently asked questions of the researcher for specific implementation suggestions with their preschool students.

Between the two professional development days, the researcher was invited in to one school to conduct demonstration lessons in four different preschool classrooms containing children ages four to five. At the request of the site director, the researcher demonstrated the use of purchased STEM learning kits on magnetism, and force and motion. In one classroom, the researcher worked alongside the teachers and set up three learning centers, placing a teacher at each station, and the children rotating through each. In the other three classrooms the teachers asked that the researcher set up one learning center in the room and rotated the children through the one center. The first situation was optimal because the classroom teachers were then engaged and fully participated in the instruction, whereas in the latter situation, the teachers were removed and only observed from a distance. As a result, the teachers in the first classroom expressed how much they enjoyed the STEAM lessons and looked forward to continued use of the learning centers.

The preschool children in all four classrooms were thrilled with the STEM learning centers and did not want to leave the center. The children were fully engaged, took turns, experimented, and communicated with the researcher and one another regarding the STEM content and phenomena that they were experiencing. The children appeared to be enjoying the STEM activities in the learning centers as they were smiling and talking excitedly with active participation.

\section{DISCUSSION AND CONCLUSIONS}

This study consisted of three research questions. The first question explored the impact of STEAM professional development on preschool teachers' dispositions towards STEM content. The findings did indicate that the teachers' dispositions towards STEM content did reflect a positive increase as a result of the workshops. This finding is in agreement with Nugent, Kunz, Rilett, and Jones (2010), who also found that teachers developed more positive attitudes towards STEM and increased their self-efficacy as a result of receiving STEM professional development.

The second research question explored the impact of STEAM professional development on preschool teachers' self-efficacy regarding planning and implementing STEAM content. The findings revealed that through the workshop, supplied resources, and modeling of the STEAM activities, the teachers did experience a positive increase in their self-efficacy regarding STEAM. Although their survey results showed a rise in their confidence and dispositions, during the interview process, teachers revealed that they still would need additional professional development in order to fully implement STEAM lessons within their classrooms. This is in agreement with Ralston et al. (2013), who found that K-12 teachers would need assistance in order to successfully implement the engineering education component of STEM. They also emphasized that simply hearing or reading about STEM was not enough, but that students and teachers alike actually need to participate in hands-on STEM training to be effective. This researcher has also found this to be true, so all of the workshops offered are hands-on and model STEAM lessons for teachers.

The third research question explored the impact of the professional development workshop on the rate of STEAM implementation by the teachers in their classrooms. It was interesting to note that after the first handson workshop, not one teacher had conducted a STEAM lesson in their classroom as a result during the two-month span, even though they were given a complete resource book filled with lessons and complete STEM learning kits for learning centers. The teachers themselves reported how much they had enjoyed the STEAM lessons and were in agreement that their preschool students would love the lessons as well, but yet they were reluctant to implement them in their classrooms. This gap between effectively educating PK-12 teachers and supporting them as they attempt to integrate their curriculum with STEM subject matter for students continues to exist even after major emphasis has been placed on STEM in recent years (Gomez and Albrecht, 2013).

These research findings showed a statistically significant change in how preschool teachers' confidence levels positively increased regarding their ability to plan and implement STEAM lessons for their preschoolers as a result of their engagement in the professional development sessions. However, even as the preschool teachers were actively engaged and experienced an increase in their knowledge, skills and dispositions regarding STEAM 
implementation, they were still reluctant to implement, as none of them implemented a STEAM lesson independently during the course of this study (self-reporting).

More research needs to be done in the area of STEAM implementation in the PK-3 classrooms as more and more states adopt the NGSS, which formally incorporates engineering education and STEM across all grade levels. Suggested research may involve investigating professional development strategies that increase the likelihood of actual classroom implementation, such as offering in-class support for teachers when implementing STEAM lessons with their children for the first time.

\section{Ethical Approval}

"All procedures performed in studies involving buman participants were in accordance with the ethical standards of the institutional and/or national research committee and with the 1964 Helsinki declaration and its later amendments or comparable ethical standards."

\section{REFERENCES}

Aronin, S. and Floyd, K. K. (2013). Using an iPad in inclusive preschool classrooms to introduce STEM concepts. Teaching Exceptional Children, 45(4), 34-39. https:// doi.org/10.1177/004005991304500404

Bagiati, A., Yoon, S. Y., Evangelou, D. and Ngambeki, I. (2010). Engineering curricula in early education: Describing the landscape of open resources. Early Childhood Research \& Practice, 12(2).

Banko, W., Grant, M. L., Jabot, M. E., McCormack, A. J. and O’Brien, T. (2013). Science for the next generation: Preparing for the new standards. Arlington, VA: National Science Teachers Association (NSTA) Press.

Becker, K. and Kyungsuk, P. (2011). Effects of integrative approaches among science, technology, engineering, and mathematics (STEM) subjects on students' learning: A preliminary meta-analysis. Journal of STEM Education: Innovations \& Research, 12(5/6), 23-37.

Bybee, R. W. and Fuchs, B. (2006). Preparing the 21st century workforce: A new reform in science and technology education. Journal of Research in Science Teaching, 43(4), 349-352. https:// doi.org/10.1002/tea.20147

City-data. (2016). Advameg, Inc. Available at: http://www.city-data.com/city/Bridgeport-Connecticut.html

Colker, L. J. and Simon, F. (2014). Cooking with STEAM. Teaching Young Children, 8(1), 10-13. Available at: http:/ / ezproxy.rowan.edu/login?url=http:/ / search.proquest.com/docview/1647823250?accountid=13605

Davidson, C. N. (2011). Now you see it: How the brain science of attention will transform the way we live, work, and learn. New York, NY: Viking.

DeJarnette, N. K. (2012). America's children: Providing early exposure to STEM (Science, Technology, Engineering and Math) initiatives. Education, 133(1), 77-83.

Desilver, D. (2015). U.S. students improving - slowly - in math and science, but still lagging internationally. Available at: http://www.pewresearch.org/fact-tank/2015/02/02/u-s-students-improving-slowly-in-mathand-science-but-still-lagging-internationally/

DeWalt, K. M. and DeWalt, B. R. (2011). Participant observation: A guide for fieldworkers. Maryland: AltaMira Press.

Gomez, A. and Albrecht, B. (2013). True STEM education. Technology \& Engineering Teacher, 73(4), 8-16.

Huffman, D., Thomas, K. and Lawrenz, F. (2003). Relationship between professional development, teachers' instructional practices, and the achievement of students in science and mathematics. School Science and Mathematics, 103(8), 378-387. https://doi.org/10.1111/j.1949-8594.2003.tb18123.x

Ingram, M. (2014). Preschoolers as engineers. Teaching Young Children, 7(3), 30-31. Available at: http:/ / ezproxy.rowan.edu/login?url=http:/ / search.proquest.com/docview/1510591523?accountid=13605

Jamil, F. M., Linder, S. M. and Stegelin, D. A. (2018). Early childhood teacher beliefs about STEAM education after a professional development conference. Early Childhood Education Journal, 46(4), 409-417. https://doi.org/10.1007/s10643-017-0875-5

Jackson, M., Heil, D., Chadde, J. and Hutzler, N. (2011). Family engineering: An activity and event planning guide. USA. Foundation for Family Science and Engineering and Michigan Technological University.

Jones, C. (2011). Children's engineering and the arts. Children's Technology \& Engineering, 16(1), 3-17.

Kazakoff, E., Sullivan, A. and Bers, M. (2013). The effect of a classroom-based intensive robotics and programming workshop on sequencing ability in early childhood. Early Childhood Education Journal, 41(4), 245255. https://doi.org/10.1007/s10643-012-0554-5

Moomaw, S. (2012). STEM begins in the early years. School Science \& Mathematics, 112(2), 57-58. https://doi.org/10.1111/j.1949-8594.2011.00119.x

Moomaw, S. and Davis, J. (2010). STEM comes to preschool. Young Children, 65(5), 12-18.

Myers, D. G. (2014). Exploring Psychology (9th Edition). New York, New York: Worth Publishers.

Myers-Spencer, R. and Huss, J. (2013). Playgrounds for the mind: Children \& libraries. The Journal of the Association for Library Service to Children, 11(3), 41-46. 
National Center for Education Statistics. (2009). Highlights from the trends in international mathematics and science studies (Rev. ed.). Washington, DC: U.S. Department of Education.

Next Generation Science. (2016). Available at: http:/ /www.nextgenscience.org/

Nugent, G., Kunz, G., Rilett, L. and Jones, E. (2010). Extending engineering education to K-12. Technology Teacher, 69(7), 14-19.

Ralston, P. S., Hieb, J. L. and Rivoli, G. (2013). Partnerships and experience in building STEM pipelines. Journal of Professional Issues in Engineering Education \& Practice, 139(2), 156-162. https://doi.org/10.1061/(ASCE)EI.19435541.0000138

Robelen, E. W. (2011). Building STEAM: Blending the arts with STEM subjects. Education Week, 31(13), 8. Available http:/ / ezproxy.rowan.edu/login?url=http://search.proquest.com/docview/910218761 ?accountid=13605

Sharapan, H. (2012). From STEM to STEAM: How early childhood educators can apply fred rogers' approach. YC Young Children, 67(1), 36-40. Available at: http:/ / ezproxy.rowan.edu/login?url=http://search.proquest.com/docview/927664843?accountid=13605

Van Meeteren, B. (2015). Engineering in preschool? The children are already working on that! Teaching Young Children, 8(3), 30-31. Available at: http:/ / ezproxy.rowan.edu/login?url=http:/ / search.proquest.com/docview/1647823064?accountid=13605

Wilson, B. G. (1996). Constructivist learning environments: Case studies in instructional design. Englewood Cliffs, NJ: Educational Technology Publications. 